\section{A Typical Case History}

A perfectly fit schoolgirl aged 14 developed a small cystic swelling on the outside of her right cheek six months previously (Fig. 1). It had been painless throughout, and after its initial appearance had remained fairly constant in size. She was seen by a consultant, who considered it to be a sebaceous cyst and treated it with carbon dioxide

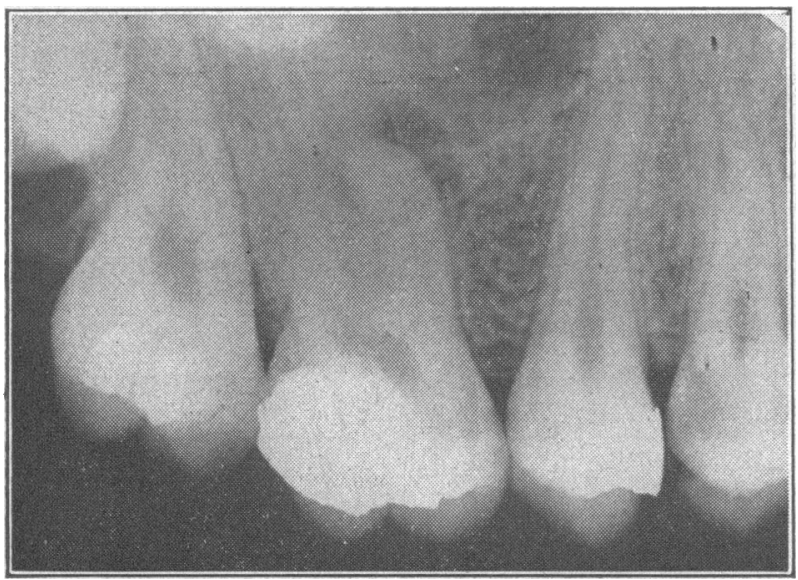

Fig. 2. $-X$-ray appearance of root infection.

snow. She was referred for plastic-surgical opinion. Examination within the mouth revealed a communicating track between the cyst and the alveolus of the upper six tooth. The teeth themselves appeared healthy, and the upper six had a filling which had been put in a year previously. There was no history of toothache. $X$-ray examination showed a quite definite root infection (Fig. 2).

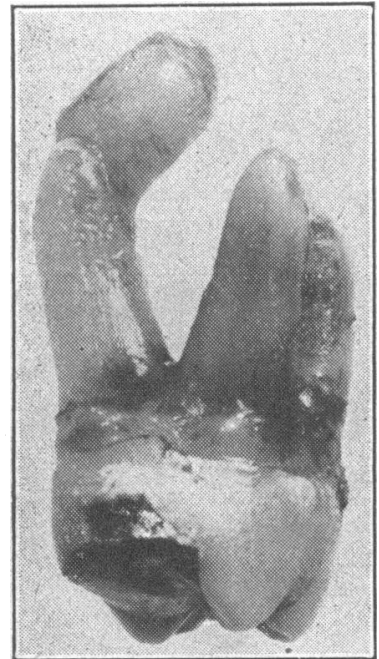

FIG. 3.-Showing chronic pulp infection.
Treatment.-Under general anaesthesia the upper six tooth was extracted; the photograph shows the chronic pulp infection with a large granuloma on the palatal root (Fig. 3). The cyst was incised and found to contain necrotic granulation tissue. Between the cyst and the alveolus was a well-defined track, and a probe inserted through the cheek presented in the base of the tooth socket. Culture of the cyst content was sterile. The facial wound healed in three days.

Comment.-Although this condition is commonplace in plastic surgery units, experience of our own cases has shown that many doctors are unaware that a silent dental infection can produce this type of lesion; hence many unsuccessful operations, aimed only at the external end of the trouble, are carried out. A dental opinion and $x$-ray examination should be a routine in all doubtful cases.

\section{C. BodenhaM, M.B., F.R.C.S.Ed} W. BAKEWELL, L.D.S.

\section{Agranulocytosis following Dapsone Therapy}

Dapsone (diaminodiphenyl-sulphone, D.A.D.P.S.) has been extensively used in the treatment of leprosy, and to-day it is considered to be the drug of choice for this disease. It was not until as recently as 1950 that Esteves and Brandão drew attention to the beneficial effects of dapsone in the treatment of dermatitis herpetiformis. Since their original publication many observers, including Cornbleet (1951), Kruizinga and
Hamminga (1953), Calnan (1954), Anning (1954), Vickers (1954), and Alexander (1955), have confirmed their findings, and dapsone is now recognized as a most valuable agent in the treatment of dermatitis herpetiformis.

The dosage of dapsone recommended has been variable, ranging from $50 \mathrm{mg}$. daily to $200 \mathrm{mg}$. daily. However, all are agreed that the dosage should be related to the clinical response. and when this has been achieved it should be replaced by a maintenance dose sufficient to suppress the clinical manifestations of the dermatosis.

The side-effects have been collected and are recorded in Table I.

Detailed investigations of the white-cell series in relation to the use of dapsone are few, and this has been confirmed by a personal communication with the manufacturers. It seems surprising that such an investigation has not appeared as a step in the preliminary therapeutic trials of this drug, which is closely related chemically to the sulphonamides. Calnan (1954) mentions agranulocytosis as a definite indication for cessation of therapy, but does not elaborate by a case history report. Fernandez et al. (1948) studied the effect on the cells of the white-cell series when dapsone was used in the treatment of leprosy, and found that the leucocyte count was either normal or indicated an increased granulopoiesis in the bone marrow. Lowe and Davey (1951) in a four-year therapeutic trial of the sulphone drugs, also in the treatment of leprosy, noted as the only white-cell abnormality an initial polymorphonucleosis, latterly mononucleosis, and other features suggestive of a sulphoninduced glandular fever.

Since no previous instance of agranulocytosis has been reported, we put the following case on record.

\section{Case Report}

A single woman of 62 was referred to the Department of Dermatology, Western Infirmary, Glasgow, on March 19, 1956, suffering from dermatitis herpetiformis of three years' duration involving the arms, legs, back, and shoulders.

Treatment with dapsone, $50 \mathrm{mg}$. daily, was prescribed, and the patient was instructed to increase the dosage to $100 \mathrm{mg}$. in a week's time. She was seen again on April 4, and, although there was a definite clinical response, the condition was not yet under control, and the dosage was increased to $125 \mathrm{mg}$. daily.

On or about April 16, whilst on holiday, the patient developed an "influenza-like illness," and from that date until her admission to hospital two weeks later she was subject to listlessness, anorexia, periodic vomiting, sore throat, and night-sweating. A blood examination on April 16 (Royal Alexandra Infirmary, Paisley) revealed Hb, 12.2 g. per $100 \mathrm{ml}$. (84\%) ; P.C.V., 36\% ; M.C.H.C., $33 \%$; and the peripheral blood film showed no abnormality. On returning home her family doctor stopped dapsone therapy (total dosage, $4.2 \mathrm{~g}$.) because of her general condition and also because a blood count carried out by him revealed a picture suggestive of agranulocytosis. She was admitted to Professor Wayne's wards, Western Infirmary, Glasgow, on April 30. where the diagnosis was confirmed.

On admission she was a rather drowsy woman showing the clinical features of dermatitis herpetiformis, and her temperature was $103^{\circ}$ F. $\left(39.4^{\circ}\right.$ C. $)$ and B.P. $120 / 45$. Purpuric lesions were present over the shoulders and arms, and the mucosae were uniformly pale. Bilateral ankle oedema and exertional dyspnoea were the only other features noted on examination of the cardiovascular and respiratory systems. The liver, spleen, and lymph nodes were not demonstrably enlarged.

Investigations. - The blood findings are recorded in Table II. The peripheral blood films showed severe leucopenia with the neutrophils virtually absent. The red cells were of normal size and well stained, while the platelets were not obviously deficient in numbers and no primitive cells of either the white or red cell series were present. The direct Coombs test was negative; blood cultures were negative ; the augmented histamine test meal showed free acid to be 
TABLE I.-Side-effects

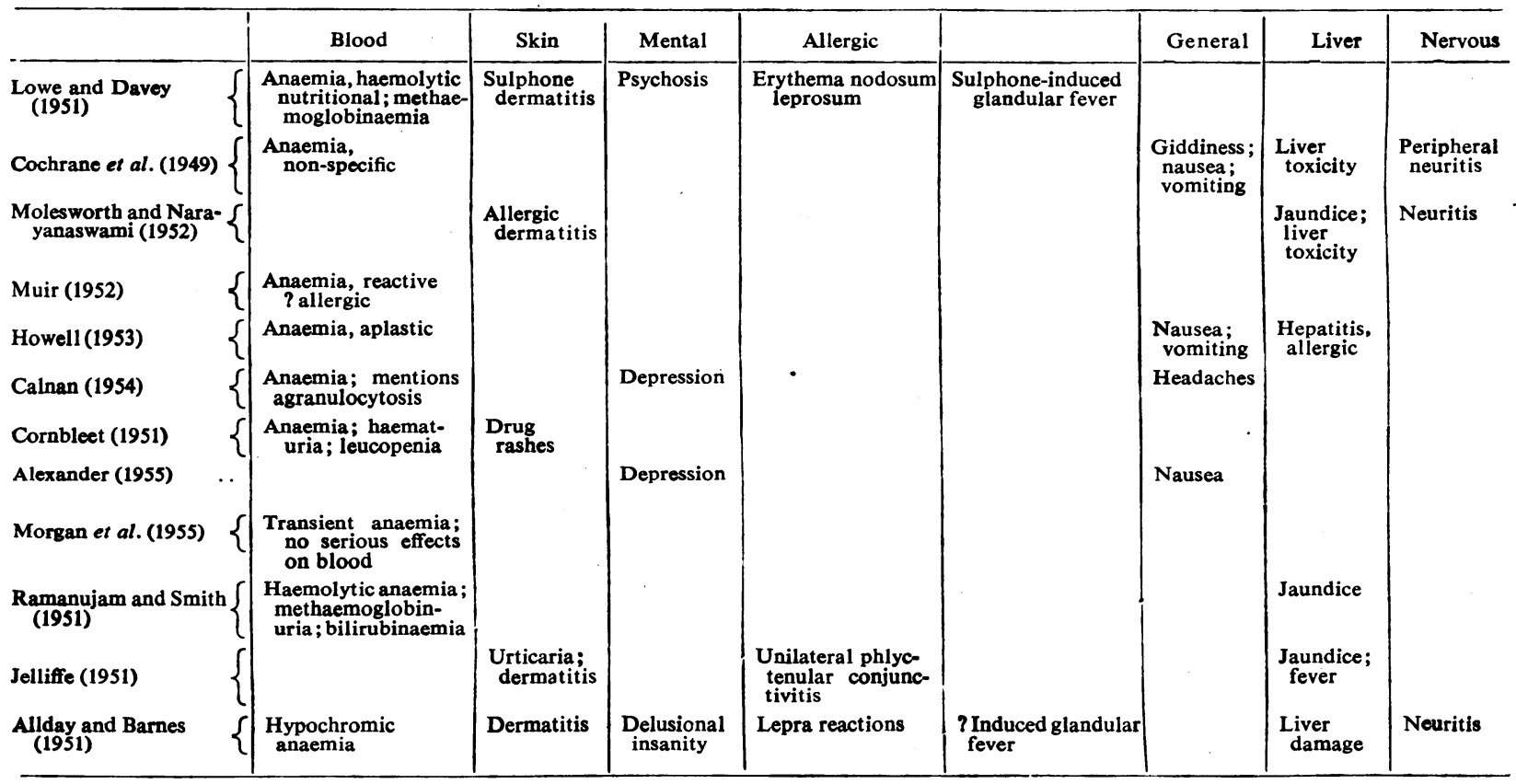

TABLE II.-Blood Findings

\begin{tabular}{|c|c|c|c|c|c|c|c|c|c|c|}
\hline & $\begin{array}{l}\text { White } \\
\text { Blood Cells } \\
\text { per c.mm. }\end{array}$ & Polymorphs & Eosinophils & $\underset{\text { Lymphocytes }}{\text { Small }}$ & $\begin{array}{c}\text { Large } \\
\text { Lymphocytes }\end{array}$ & Monocytes & g. $/ 100 \mathrm{ml}$. & P.C.V. & M.C.H.C. & E.S.R. \\
\hline $14 / 4 / 56$ & & & & & & & $12 \cdot 2$ & $36 \%$ & $33 \%$ & \\
\hline $30 / 4 / 56$ & 1,500 & 0 & 0 & $\begin{array}{l}900 \\
90 \text { smea }\end{array}$ & $\begin{array}{r}210 \\
\text { ar cells) }\end{array}$ & 300 & $8 \cdot 9$ & $28 \%$ & $31 \cdot 7 \%$ & \\
\hline $11 / 5 / 56$ & 6,100 & $.1,952$ & 0 & 3,599 & 0 & 549 & $10 \cdot 4$ & $36 \%$ & $28.9 \%$ & $6 \mathrm{~mm} . / \mathrm{hr}$. \\
\hline $18 / 5 / 56$ & 8,800 & 4,488 & 88 & $\begin{array}{l}3,080 \\
\text { (88 smea }\end{array}$ & $\begin{array}{l}440 \\
\text { ar cells) }\end{array}$ & 616 & 12.6 & $40 \%$ & $31 \cdot 2 \%$ & $16 \quad$ \\
\hline $27 / 8 / 56$ & 7,900 & 3,239 & 948 & 3,239 & 79 & 395 & $13 \cdot 6$ & $42 \%$ & $32.4 \%$ & \\
\hline
\end{tabular}

present after histamine; the urine contained a few granular casts; urobilinogen and acetone were present.

Treatment and Progress.-The patient was treated with 500,000 units of crystalline penicillin six-hourly from April 30 to May 14, and on admission a fresh whole-blood transfusion of two pints $(1.14 \mathrm{l}$.) was given within two to four hours of withdrawal from the donor in the hope of obtaining cells of the white-cell series in a vital and active state. On May 2 sternal marrow puncture showed a picture typical of agranulocytosis of the aplastic type. Mature white cells were absent and their precursors virtually absent, while there was no apparent diminution in the red-cell precursors. The megakaryocytes were not reduced.

The patient made an uneventful recovery and was discharged from hospital on May 18. At a follow-up on August 27 the peripheral blood film showed the eosinophilia usually found in dermatitis herpetiformis and normocytic normochromic haemopoiesis. Both the platelets and reticulocytes were within normal limits. The sternal marrow revealed normal erythroblastic haemopoiesis and normal maturation of the white-cell series. Sections of the marrow fragments showed no hyperplasia. Two lymphoid follicles were present in the stained marrow sections.

\section{COMMENT}

From the sternal marrow and peripheral blood examinations on admission there appeared to be a normal erythroblastic red-cell maturation and platelet production. The agranulocytosis was aplastic in type rather than a maturation defect. Various authors have described a hypochromic and a haemolytic form of anaemia associated with dapsone therapy. The anaemia in our case did not appear to con- form to either of these types. It was probably due to a toxic depression of the bone marrow of a similar nature to that which produced the agranulocytosis.

We consider this case to be dapsone-induced agranulocytosis for several reasons. Dermatitis herpetiformis does not itself produce agranulocytosis, and there was no recent contact with any other drug known to produce agranulocytosis ; the onset of the disease was rapid; complete recovery followed the withdrawal of the drug; the agranulocytosis was of aplastic type.

We wish to thank Dr. R. Massey for bringing this case to our notice, and Professor E. J. Wayne for his help and permission to publish this case. We also thank Dr. Hutchison for his assistance with the haematological findings.

William B. McKenNa, M.D.,

A. C. Chalmers, M.B., Ch.B., Western Infirmary, Glasgow.

REFERENCES

Anning, S. T. (1954). Med. Ill. (Lond.) 8, 645 .

Allday, E. J., and Barnes, J, (1951). Lancet, 2, 205.

Alexander, J. O'D. (1955), Ibid. 1, 1201.

Cornbleet, T. (1951). A.M.A. Arch. Derm. Syph., 64, 684.

Calnan, C. D. (1954). Trans. St. John's Hosp. Derm. Soc., No. 33, 53. Cochrane, R. G., Ramanujam, K., Paul, H., and Russeli, D. (1949). Leprosy Rev., $20,4$.

Esteves, J., and Brandão, F. N. (1950). Trab. Soc. port. Derm., 8, 209. Fernandez, J. M. M., Carboni, E. A., Tommasino, P., and Gimenez, M. M. (1948). Int. J. Lep., 16, 319.

Howell, R. G. (1955). Brtt. med. J., 1, 542.

Jelliffe, D. B. (1951). Lancet, 1, 1343 .

Kruizinga, B. E., and Hamminga, H. (1953). Dermatologica, 106, 387. Lowe, J., and Davey, T. F. (1951). Trans. roy. Soc. trop. Med. Hyg., 44.

Molesworth. B. D., and Narayanaswami, P. S. (1952). Lancet, 1, 562.

Muir, E. (1952). Trans. roy. Soc. Trop. med. Hyg., 46,113 .

Morgan. J. K., Marsden, C. W., Coburn, J. G., and Mungavin, J. M. (1955). Lancet, 1, 1197.

Ramanujam, K., and Smith, M. (1951). Ibid., 1, 21

Vickers, H. R. (1954). Practitioner, 173, 373. 